\title{
Dossî̂
}

APRESENTAÇÃO 


\section{EN TORNO DE UNA PERSPECTIVA GLOTOPOLITICA: DIÁLOGOS, INVESTIGACIONES, ACCIONES}

El dossier de este número 20 de la revista Caracol propone la discusión sobre el funcionamiento de lo político con relación a las diferentes prácticas que se inscriben en el universo del lenguaje. Así, varios de los trabajos reunidos adoptan y/o tematizan la perspectiva glotopolítica en las direcciones en que, a partir de la reflexión fundadora de Guespin e Marcellesi de los años 80 , viene siendo trabajada y resignificada en una serie de líneas de investigación, de publicaciones y en espacios profesionales, tales como el del $4^{\circ}$ Congreso Latinoamericano de Glotopolítica (4º CLAGlo), realizado en septiembre de 2019 en la Universidad de Sáo Paulo. De las presentaciones de este evento resulta, justamente, la constitución del referido dossier.

En este sentido, varios artículos plantean y exploran alianzas teóricas vistas como necesarias por la productividad que prometen; discuten los desafíos impuestos por procesos políticos que afectan el funcionamiento del lenguaje, en términos tanto conceptuales como de modalidad de análisis; y reflexionan sobre las condiciones materiales de la producción del conocimiento lingüístico y del desarrollo de la educación lingüística, atendiendo al rol que las escuelas hegemónicas de estudios del lenguaje juegan en la exclusión (o no) de prácticas de investigación y docencia cuyo punto de partida es el reconocimiento del carácter político del lenguaje.

El artículo de Elvira Narvaja de Arnoux abre el dossier. En "Glotopolítica: balances y perspectivas en el contexto del $4^{\circ}$ CLAGlo" la autora, primero, aborda el proceso de constitución de esa línea de trabajo en la Argentina, 
manteniendo un claro diálogo con lo que las condiciones históricas de la segunda mitad del siglo pasado imponían en términos de producción de conocimiento en el campo de los Estudios del lenguaje. En un segundo momento se detiene en el análisis de los temas y problemáticas que se hicieron presentes en el propio congreso, especialmente en las mesas plenarias y, por último, traza la proyección de posibles desdoblamientos de la reflexión allí desarrollada. El artículo de Roberto Bein, "Síntesis temática del 4o Congreso Latinoamericano de Glotopolítica”, viene a complementar y ampliar el trabajo de esa mirada que se vuelca sobre el propio congreso. En ese texto, como lo indica su título, el autor realiza una lectura del evento a partir de la delimitación de tres temáticas determinadas como resultado de su escucha. Así mismo, a partir de su interpretación, llega a considerar conceptos que enriquecerían el análisis glotopolítico y a señalar aspectos o temáticas que, pudiendo haber estado presentes, no fueron contempladas en las diversas presentaciones de la respectiva edición del congreso.

Esos dos textos formaron parte de la mesa de cierre del evento - "Glotopolítica - balances y perspectivas"- y su lectura brinda un panorama general del mismo. Los que presentaremos a seguir acompañan, en buena parte, la organización y las presentaciones de las otras mesas plenarias organizadas para la ocasión.

En el artículo "La memoria dictatorial en el discurso de la gestión Macri (Argentina, 2015-2019)”, Mariana di Stefano aborda el análisis del discurso político a partir del enfoque glotopolítico. Para ello, parte de la hipótesis de que la memoria dictatorial de los años 70 actúa como reguladora de la 
construcción de objetos de discurso en el área de "la seguridad interior" y se hace presente en el discurso de la gestión de Mauricio Macri (2015-2019), especialmente en lo que se refiere a la cuestión del "enemigo interior", en relación a la cual la enunciación macrista recupera la fórmula dictatorial "subversión marxista/comunista". Ese trabajo formó parte de la mesa de abertura del 40 CLAGlo: "América Latina: dependência, atualidade e memória”, en la que también se hacía necesario el tratamiento de un concepto relevante para el enfoque glotopolítico. En ese sentido, a partir de una reflexión realizada en el campo de la sociología y de su experiencia como militante revolucionario, Luiz Fernando da Silva aporta al dossier una reflexión alrededor de "Imperialismo e dependência estrutural latino-americana: alguns aspectos conceituais, históricos e contemporáneos”. En ese artículo, discute la "dependencia estructural” de América Latina, presentando una síntesis de la evolución de esta perspectiva analítica que permitió, desde la década de 1920, un eje diverso de interpretaciones sobre las desigualdades, la miseria social y el atraso económico en la región. Cabe registrar que el autor subraya la actual ausencia del tema en los medios académicos y en gran parte de la izquierda política de América Latina, destacando que la globalización no eliminó sino que profundizó la dependencia estructural del subcontinente.

Tres artículos de este dossier son resultado de las presentaciones de una mesa que fue especialmente importante y productiva en el $4^{\circ}$ CLAGlo: "Activismo y lenguas indígenas". En el primero de ellos, "Lengua y territorio: Relación estratégica para la revitalización del mapuzugun”, Viktor 
Naqill Gomez aborda aspectos del proceso de revitalización del mapuzugun que tiene lugar desde 2008 tanto en Walmapu, País Mapuche, como en la diáspora mapuche. El autor formula una clara definición de "revitalización lingüística”, colocando en cuestión el gesto de oficialización que en muchos estados americanos no logra detener el declive de las lenguas indígenas. En ese sentido, defiende que la revitalización de una lengua solo es posible si esta tiene el estatuto de oficial y es lengua de enseñanza en un marco político-territorial definido. Por su parte, en el artículo "Educación intercultural: la perspectiva de los pueblos indígenas de Bolivia”, Valentín Arispe presenta un análisis de las acciones que vienen siendo realizadas en Bolivia a partir del reconocimiento del carácter plurinacional e intercultural de ese Estado -materializado en la Constitución Política de 2009- para implementar el modelo de Educación Intercultural Bilingüe (EIB). Después de abordar sus avances y desafíos, el autor destaca la importancia de que tales iniciativas sean realizadas en tanto política de Estado. Cerrando la temática "Activismo y lenguas indígenas", el texto "Educação Guarani e interculturalidade: a(s) História(s) Nhandeva e o Teko", de Sandra Benites, fue elaborado a partir de la transcripción de su intervención en la misma mesa plenaria. En este sensible texto, la educadora y activista indígena guaraní nhandeva, al considerar las relaciones entre la educación guaraní y el sistema educativo del Estado brasileño, propone una discusión de la noción de interculturalidad en las escuelas interculturales que funcionan en territorios indígenas, defendiendo la necesidad de que las prácticas pedagógicas desarrolladas en ese ámbito se centren en el diálogo con la diferencia. 
El próximo artículo del dossier se vincula a la mesa plenaria "Línguas e hegemonias". Se trata de "Hacia una apuesta etnográfica para la glotopolítica", en el que Virginia Zavala argumenta a favor de que la perspectiva histórica y crítica adoptada por la Glotopolítica podría enriquecerse con el enfoque etnográfico de la sociolingüística crítica y la antropología lingüística del norte global, dentro de un proyecto contra hegemónico. Al abordar una disputa por la representación del quechua entre dos tipos de comunidades de práctica involucradas en el desarrollo de políticas lingüísticas en el Perú, Zavala sostiene que la etnografía permite explicar mejor los procesos implicados en la construcción de ideologías lingüísticas, concepto caro a la Glotopolítica.

Los dos artículos siguientes se vinculan a la mesa plenaria "Español, guaraní, portugués: intervenciones glotopolíticas”. Hedy Penner, autora de "Gestión glotopolítica del Paraguay: ¿primero normativizar, después normalizar?", analiza, en el marco del proceso de implementación de la Ley de lenguas de 2010, las implicaciones de la prioridad dada a las acciones de normativización del guaraní en detrimento de las de su normalización. Al examinar cuestiones referentes a la adopción de un alfabeto de 33 letras, la autora cuestiona la aplicabilidad de las reglas ortográficas propuestas por la "Academia de la Lengua Guaraní” en 2015. Por su parte, en "Dispositivo semiótico e investigación glotopolítica: Relato de Experiencias de Vivir entre-lenguas.", Liliana Silvia Daviña entrelaza estudios discursivos, semióticos y glotopolíticos para abordar un espacio urdido por especiales tramas históricas y lingüísticas. Se trata de uno de los vecindarios fronterizos de la región sudamericana, como ella misma los denomina, el de Misiones 
(Argentina). En este sentido, de un corpus mayor, retira relatos testimoniales que le permiten interpretar discursivamente lazos semióticos entre memoria y presente o, más precisamente, entre la memoria y la experiencia de vivir entre-lenguas.

Por último, dos textos presentados en el $4^{\circ}$ CLAGlo cierran nuestro dossier. En su artículo "A Língua Espanhola no Brasil: ruptura e resistência do elo língua-cultura", Greice de Nóbrega e Sousa muestra cómo las políticas lingüísticas que giran en torno a las lenguas extranjeras se materializan, en tanto directrices curriculares y materiales didácticos, en el discurso pedagógico sobre la lengua espańola en Brasil. Por medio del análisis de actividades con canciones propuestas en diferentes materiales didácticos brasileños para la enseñanza de español en el nivel secundario, la autora detecta una regularidad en ese discurso: el "enlace lengua-cultura", representado por las formas en que la lengua es colocada en relación con los procesos socio-históricos vividos por pueblos hispanohablantes. Por su parte, en su artículo "A expansão linguística espanhola na China e no Brasil: convergências, deslocamentos e assimetrias", Andrea Silva Ponte compara los procesos de expansión lingüística llevados a cabo por el Estado español en Brasil y en la China: en el primer caso, a fines de los años 90 y comienzos de los 2000 y, en el segundo, en la actualidad. Por medio del análisis de ciertos ideologemas y de los sistemas ideológicos con los que estos entran en filiación, la autora revela los procesos político-lingüísticos y las posiciones sociales, históricas y políticas que marcan la construcción y la manutención del valor simbólico de la lengua espańola en el mundo. 
Tanto el $4^{\circ}$ CLAGlo como el presente dossier revelan, en definitiva, el carácter del proyecto glotopolítico en el que están inscritos al renunciar a pretensiones de dogmatismo disciplinario y abrazar en su lugar el compromiso con prácticas de trabajo y diálogo en las que el ejercicio intelectual, pedagógico y comunitario resultan inseparables. El estudio de la compleja articulación entre el lenguaje en todas sus manifestaciones y lo político en todas las suyas se nutre de experiencias sociales que abarcan desde la educación lingüística (la enseñanza del español a hablantes de otras lenguas, por ejemplo) hasta el ejercicio de la política en sus sentidos más latos (valga el caso del debate en el contexto de la pugna electoral entre partidos). Pero a la vez, la adopción de la perspectiva glotopolítica en la investigación significa, bien lejos de acomodarse en el tan frecuente narcisismo autocontemplativo académico, volcar la reflexión sobre la infinidad de prácticas en las que se pone en juego la constitución de subjetividades políticas (incluidas las prácticas propias de la investigación académica) y por ende la distribución de recursos y acceso a los resortes que mueven nuestras sociedades (y nuestras universidades) hacia lugares más justos donde el ethos colectivista venza a las pulsiones del interés personal y la ley del más fuerte.

Luego del dossier, la sesión "Varia" de este número de Caracol trae un total de trece artículos: uno del ámbito de los estudios lingüísticos, otro de la literatura española y una mayor proporción de textos sobre literatura y fenómenos culturales del ámbito hispanoamericano e, incluso, latinoamericano.

Abre la sección el primero de ellos: "De pive a pibe chorro. El uso de pibe en el espańol rioplatense", un artículo en el cual Malena Velarde aborda 
la etimología de la palabra pibe en el funcionamiento de la lengua de ese ámbito. Para concluir con relación a la controversia de la que fue objeto y a los sentidos que el término guarda en la actualidad, la autora recorre obras lexicográficas y, también, diversas textualidades retiradas de medios gráficos $\mathrm{y}$ de producciones culturales.

Sigue el texto "José María Arguedas y la Revista Pumaccahua: creación literaria e investigación etnográfica”, en el cual Nécker Salazar Mejía analiza la concepción pedagógica que Arguedas puso en práctica en el Colegio Nacional Mateo Pumaccahua, de Sicuani, en el Cusco, entre los años 1939 y 1941. Incluye en su estudio la publicación de la revista Pumaccahua, un producto de esa experiencia pedagógica que le permite concluir que la escuela puede ser un lugar propicio para la creación, la reflexión y la investigación.

Andrea Cabel García, en "Jum, el indio impensable de La casa verde y de Mario Vargas Llosa", presenta una lectura desde los estudios postcoloniales y subalternos de La casa verde (1966), segunda novela del escritor peruano Mario Vargas Llosa, centrándose en el análisis del personaje principal, Jum, el cacique aguaruna que encarna un paradigma complejo de la indigenidad amazónica.

Dos textos presentan análisis de diferentes objetos del clásico argentino Martín Fierro, de José Hernández. Daniela Dorfman, en el artículo "Una épica relevante: la cultura legal argentina y las escenas judiciales del Martín Fierro", presenta los modos en que la literatura argentina del siglo XIX articula las relaciones de los habitantes con el Estado y con la ley a partir del estudio de las escenas judiciales en la obra; y Sara Iriarte, en "El mito gaucho 
y la construcción de las identidades nacionales: proyecciones en traducciones y reescrituras extranjeras del Martín Fierro", explora las proyecciones del mito gaucho, fundante de la identidad nacional argentina, en traducciones y reescrituras angloamericanas, brasileñas e italianas de la obra.

En "Voces femeninas en la guerra de independencia de Cuba: Lila de Luáces y Eva Adán de Rodríguez”, Jorge Camacho discute las formas de representar la violencia y el "yo" en las narraciones de Lila de Luáces y Eva Adán de Rodríguez, composiciones que funcionan como testimonios de la primera guerra de independencia de Cuba (1868 y 1878) y que operan como contrapeso a la historia oficial contada por el poder español en la isla.

Lluís Agustí y Pedro Rueda Ramírez, en el texto "La Colección Aquelarre: editar en México después del naufragio”, presentan un análisis de 19 obras editadas entre 1950 y 1954 por esa editorial, surgida a partir de la tertulia del mismo nombre que un grupo de refugiados republicanos españoles mantuvieron en Ciudad de México.

En su artículo “La Malinche sob a visão de José Limón”, Dóris Giacomolli aborda, a partir del libro José Limón and La Malinche: The dancer and the Dance (2008) de Patricia Seed, aspectos del espectáculo La Malinche, de autoría del coreógrafo mexicano José Limón. La autora se concentra, fundamentalmente, en analizar la forma en la que está construido el personaje central de la Malinche.

En "Saer en París: un modernista camina las calles de Mayo del 68”, Carolina Maranguello aborda los poemas que Juan José Saer escribe en París en un viaje de 1968, inicialmente de estudios pero que se prolonga por 
el resto de su vida. Las composiciones ponen en escena a un sujeto que se desplaza por esa ciudad y que se desdobla en una serie de escritores-viajeros, fundamentalmente Rubén Darío.

Luciene Azevedo, en el ensayo "Ficção e filosofia em Las Conversaciones de César Aira”, parte de una reflexión sobre la noción de verosimilitud tomando pasajes de clásicos como La República de Platón y la Poética de Aristóteles, para abordar la novela Las conversaciones (2007), de César Aira. La autora explora la remisión metaficcional, marca -según ella misma- de autoría de este escritor, como una oportunidad para la reflexión más amplia sobre el modo de funcionamiento de la literatura y sobre las relaciones con el realismo y el elogio de los mundos imaginados por la ficción.

En "El silencio y el ruido: dos modos de habitar el mundo contemporáneo en la cuentística de Roberto Bolaño", Mariela Fuentes Leal se concentra en "Sensini" y "Una aventura literaria", dos cuentos de Llamadas telefónicas, de ese escritor. En ambas narrativas, en las que la sociedad se articula por el horror transfigurado en su perpetuidad, la autora se detiene en el tratamiento del silencio como mecanismo de resistencia frente al mercado y en el ruido, en tanto eco de esa violencia.

Sofía Bonino, en el artículo "La(s) lectura(s) en la obra de Manuel Vicent: biografía literaria e imagen de autor”, realiza una reconstrucción de la biografía literaria de ese autor a partir de dos novelas -Tranvía a la Malvarrosa (1994) y Verás el cielo abierto (2005) - y de artículos periodísticos que tematizan la lectura y los autores que han sido pilares en la formación literaria del autor. 
Cierra la varia de este número un artículo que coloca en diálogo la obra de dos autores del espacio sudamericano. En "Machado de Assis e Jorge Luis Borges: dois classicistas em plena Modernidade”, André Luiz Barros analiza el tono clasicista de los narradores (y de algunos personajes) de ambos autores, haciendo foco en las elecciones y procedimientos estéticos singulares de cada uno de ellos.

El número concluye con dos reseñas. La primera, de autoría de Vinícius de Oliveira, versa sobre Arenas Movedizas, de Octavio Paz, traducida al portugués por André Caramuru Aubert e ilustrada por Gabriel Pacheco (São Paulo: SESI-SP Editora, 2018, 64 p.). La segunda, de autoría de Daniel Carlos Santos da Silva, sobre la publicación bilingüe Desglaç/Degelo, de la obra de Maria-Mercè Marçal (Bragança Paulista: Urutau, 2019, 214 p.). En este caso, la traducción del catalán al portugués estuvo a cargo de Meritxell Hernando Marsal y de Beatriz Regina Guimarães Barboza.

José del Valle Fernanda Castelano Rodrigues María Teresa Celada 